Clinical and physiological assessment of asthmatic children treated with beclomethene diproprionate. F Allergy Clin Immunol 1976;57:112-23.

4 Kershnar H, Klein R, Waldman D, et al. Treatment of chronic childhood asthma with beclomethasone diproprionate aerosols. II. Effect on pituitary-adrenal function after substitution for oral corticosteroids. Pediatrics 1978;62:189-97. depending on their routes of administration. Ann NY Acad Sci 1971;179: $108-12$

6 Martin LE, Tanner RJN, Clark TJH, Cochrane GM. Absorption and metabolism of orally administered beclomethasone diproprionate. Clin Pharmacol Ther

7 Harris DM, Martin LE, Harrison C, Jack D. The effect of intranasal beclomethasone diproprionate aerosol on adrenal function. Clin Allergy 1974;4:291-4.

8 Mygind N, Sorensen H, Pedersen CB. The nasal mucosa during long-term reatment with beclomethasone diproprionate aerosol. Acta Otolaryngol $1978 ; 85: 437-43$

Kerrebijn KF. Beclomethasone diproprionate in long-term treatment of asthma in children. F Pediatr 1976;89:821-6.

10 Godfrey S, Balfour-Lynn L, Tooley $M$. A three to five year follow-up of the use of the aerosol steroid beclomethasone diproprionate in childhood asthma. $\mathcal{f}$ Allergy Clin Immunol 1978;62:335-9.
11 Bhan GL, Gwynn CM, Morrison Smith J. Growth and adrenal function of children on prolonged beclomethasone diproprionate treatment. Lancet 1980;i:

12 Wyatt $R$, Waschek J, Weinberger $M$, Sherman B. Effects of inhaled beclomethasone diproprionate and alternate-day prednisolone on pituitary-adrenal function in children with chronic asthma. New Engl F Med 1978;299:1387-92.

13 Harris DM, Martin LE, Harrison C, Jack D. The effect of ori and inhaled beclomethasone diproprionate on adrenal function. Clin Allergy 1973;3: 243-8.

14 Francis RS. Adrenocortical function during high-dose beclomethasone aerosol treatment. Clin Allergy 1984;14:49-53.

15 Paganelli R, Levinsky RJ, Brostoff J, Wraith DG. Immune complexes containing food proteins in normal and atopic subjects after oral challenge and effect of sodium cromoglycate on antigen absorption. Lancet $1979 ; \mathrm{i}: 1270-2$.

16 Jackson PG, Lessof MH, Baker RWR, Ferret J, MacDonald DM. Intestinal permeability in patients with eczema and food allergy. Lancet 1981; i:1285-6. 7 Ukaban SO, Mann RJ, Cooper BT. Small intestinal permeability to sugars in patients with atopic eczema. $B r \mathcal{F}$ Dermatol 1984;110:649-52.

(Accepted 15 fune 1984)

\title{
Acute cholecystitis and thiazides
}

\author{
WILLEM VAN DER LINDEN, BERND RITTER, GUNNAR EDLUND
}

\begin{abstract}
Drugs purchased by a random sample $(17000)$ of the population of Jämtland county, Sweden, are continuously monitored. Patients who had been admitted to the county's only hospital with acute cholecystitis and who were part of this sample were studied, and controls matched for age and sex were drawn from the sample. The purchase of thiazides and other drugs prescribed to the patients with acute cholecystitis was compared with that of the controls. The estimated relative risk of developing acute cholecystitis in patients who had purchased thiazides in the year before admission to hospital, as compared with those who had not, was $2 \cdot 1$ (95\% confidence limit 1.1-3.9).

As it has been reliably reported that the use of thiazides is not itself associated with cholelithiasis, the association found between thiazides and cholecystitis suggests that thiazides may increase the risk of acute cholecystitis developing in a patient with gall stones.
\end{abstract}

\section{Introduction}

Case-control studies of lifetime drug histories have provided evidence both for and against the view that use of thiazides is associated with cholecystitis. ${ }^{12}$ We were able to take a different approach by taking advantage of the continuous recording of all purchases of drugs prescribed to a random sample of the population of the county served by our hospital, and of the fact that residents of the county with acute cholecystitis are treated only at this hospital.

\section{Patients and methods}

From 1 April 1974 to 31 August 1983, 728 patients were treated at Ostersunds Sjukhus, the only hospital in the county, for acute cholecystitis. The regulations of the Swedish health service do not permit residents of one county to be admitted to hospitals outside that county

Departments of Surgery and Internal Medicine, Östersunds Sjukhus, S831 83 Östersund, Sweden

WILLEM VAN DER LINDEN, MD, professor of surgery

BERND RITTER, MD, consultant, department of internal medicine

GUNNAR EDLUND, MD, consultant, department of surgery

Correspondence to: Professor van der Linden. unless they fall ill elsewhere. As we have a policy of performing early cholecystectomy the diagnosis was confirmed at operation in most cases. ${ }^{3}$ In the few patients in whom this was not so all the symptoms and signs of acute cholecystitis had been present but the gall bladder was not visualised at cholecystography or cholescintigraphy, or ultrasonography indicated the presence of gall stones.

Since 1970 a record has been kept of all prescribed drugs dispensed to a sample of residents of the county. This sample, selected on the basis of date of birth, constitutes $13 \%$ of the entire population of the county. ${ }^{4}$ The subjects are identified by number and their records arranged according to date of birth. Pharmacies record and file on computer all prescriptions dispensed to these subjects. ${ }^{5}$

During the period under study 91 patients admitted to hospital with acute cholecystitis also formed part of the random sample whose purchase of drugs was being monitored. Forty four were men and 47 women, and their median age was 65 . For each of these 91 patients the next four subjects of the same sex were taken from the random sample and served as controls. As the subjects in the random sample are arranged according to date of birth the controls were closely matched for age. These controls had not been treated for acute cholecystitis during the period under study. A review was conducted of drugs purchased either recently or in the past by the 91 patients and the 364 controls. Recent purchase was defined as the purchase of a prescribed drug within one year of the patient's admission to hospital. Past purchase was defined as the purchase of a drug one to five years before the patient's admission to hospital. Patients and controls were compared for their recent and past purchase of thiazides, non-thiazide diuretics, nitrofurantoin, steroid ointment, and nitrazepam. The case histories of the 91 patients with acute cholecystitis were reviewed, and the clinical, radiological, and operative findings in those who had purchased thiazides before admission were compared with the findings in those who had not. Relative risks and $95 \%$ confidence limits were calculated. ${ }^{6}$

\section{Results}

The table shows how many of the 91 patients with acute cholecystitis and the 364 controls had purchased thiazides recently, in the past, or not at all and gives the relative risk and $95 \%$ confidence limits for each group. The relative risk for recent purchase was $2.1(95 \%$ confidence interval 1.1-3.9). A further subdivision based on the number of years over which purchase had taken place showed that the relative risk increased with time, but this was not analysed statistically as the numbers were small. No significant association was found between past purchase and acute cholecystitis (table).

The records showed that non-thiazide diuretics had been purchased recently by seven of the patients with acute cholecystitis and 30 of the controls. The estimated relative risk was 0.9 (95\% confidence limits $0 \cdot 4-2 \cdot 1)$. Past purchase of non-thiazide diuretics had been recorded in only two patients and 17 controls, giving a relative risk estimate of 0.5 with a $95 \%$ confidence interval including unity. The proportion of patients with acute cholecystitis who had made recent purchases of 
nitrazepam, steroid ointment, and nitrofurantoin corresponded closely to the proportion of controls who had purchased these drugs. The estimated relative risk was 0.9 for the three drugs. Similarly, there was little difference in the proportions of patients and controls who had made past purchases of these drugs. The estimated relative risks for past purchase of nitrazepam, steroid ointment, and nitrofurantoin were $1.3,0.8$, and 1.4 respectively, and the confidence intervals included unity.

The 18 patients who had recently purchased thiazides comprised eight men and 10 women aged 52-84 with a median age of $67 \frac{1}{2}$. The 67 patients who had never purchased thiazides comprised 32 men and 35 women aged 49-74 with a median age of 63. A comparison of the case histories of the 18 patients who had recently purchased thiazides with those of the 67 patients who had never purchased these drugs showed little difference in the occurrence of high fever, common duct stones, and perforation of the gall bladder and in serum amylase activities. Gall stones were found in 17 of the 18 patients who had recently purchased thiazides. Perforation of the gall bladder had occurred in two of the 18 patients.

Recent and past purchases of thiazides by patients with acute cholecystitis and controls

\begin{tabular}{lcccc}
\hline & $\begin{array}{c}\text { Recent* } \\
\text { purchase }\end{array}$ & $\begin{array}{c}\text { Past } \\
\text { purchase }\end{array}$ & $\begin{array}{c}\text { All } \\
\text { purchases }\end{array}$ & $\begin{array}{c}\text { No } \\
\text { purchase }\end{array}$ \\
\hline Patients $(n=91)$ & 18 & 6 & 24 & 67 \\
Controls $(n=364)$ & 38 & 30 & 68 & 296 \\
Relative risk & $2 \cdot 1$ & $0 \cdot 9$ & $1 \cdot 6$ & \\
$95^{\circ}{ }_{0}$ confidence limit & $1 \cdot 1-3 \cdot 9$ & $0 \cdot 3-2 \cdot 3$ & $0 \cdot 9-2 \cdot 7$ & \\
\hline
\end{tabular}

*Recent purchase: within one year of admission to hospital.

+ Past purchase: one to five years before admission to hospital

\section{Discussion}

For technical reasons we divided the drugs into those purchased recently-that is, within one year of the patient's admission to hospital-and those purchased in the pastthat is, one to five years before the date of admission. Recent purchase of thiazides was found to increase the risk of acute cholecystitis (table). This finding accords with the findings of Rosenberg et al on the use of thiazides during the month before admission. ${ }^{1}$

It might be surmised that patients who are at risk of developing acute cholecystitis would purchase drugs of all sorts more often than other people. Our data showed that this was not so, as the proportion of patients with acute cholecystitis who had recently purchased nitrazepam, non-thiazide diuretics, nitrofurantoin, and steroid ointment corresponded closely to the proportion of controls who had recently purchased these drugs. Only thiazides had been purchased by a higher proportion of patients with acute cholecystitis than controls. It might also be argued that patients with mild acute cholecystitis are more likely to be admitted to hospital if in addition they suffer from a condition that leads to the use of thiazides. If that were the case we would have found a higher proportion of patients with mild acute cholecystitis among those who had purchased thiazides than among those who had not. Comparison of the case histories showed that if any difference existed it was the other way round.

Rosenberg et al found that the relative risk of acute cholecystitis increased with prolonged use of thiazides. ${ }^{1}$ Our figures showed a similar trend, but the numbers were too small for statistical analysis. Also like Rosenberg et al, we found no significant association between acute cholecystitis and past purchase of thiazides (table). ${ }^{1}$ Rosenberg et al found that the relative risk had returned almost to unity only one month after thiazides were stopped. ${ }^{1}$ This means that acute cholecystitis is not associated with conditions such as hypertension that lead to use of thiazides. Clearly, an association between two diseases, whether true or spurious, will not vanish just because treatment is stopped or changed, and so the results of Rosenberg et al do not conform with "Berkson's fallacy." " Rosenberg et al compared two disease groups-that is, patients with acute cholecystitis with controls drawn from patients in hospital for other reasons-to ascertain the occurrence of a third disease-that is, conditions requiring thiazides. When such comparisons are made in hospitals the results can be highly misleading. ${ }^{\text {? }}$

The rapid return to normal of the risk of cholecystitis when treatment with thiazides is stopped is incompatible with the hypothesis that thiazides may induce gall stones, thus causing cholecystitis. Gall stones rarely resolve spontaneously: if thiazides did induce gall stones a patient would be at risk of developing cholecystitis for the rest of his life regardless of whether he continued the drug. The return to normal of the risk when treatment is stopped is, however, compatible with the hypothesis that thiazides temporarily increase the risk of developing acute cholecystitis in a patient with gall stones. Porter et al denied that the use of thiazides was associated with acute cholecystitis. ${ }^{2}$ They based their conclusions on the results of a study of drug histories and data on members of a medical cooperative. The cooperative had filed data on diagnoses at discharge from hospital and on the members' purchases of drugs. Unlike the sample studied here, however, the cooperative is not a random sample of the population, and recent evidence suggests that medical cooperatives selectively attract people for whom the costs of medical care are lower and who may in fact be healthier than others. ${ }^{8}$ Such selection will tend to eliminate people with gall stones who also need thiazides and, consequently, will tend to eliminate an association between use of these drugs and acute cholecystitis. The data from the study of drug histories conducted by Porter et al yielded a relative risk estimate of $1 \cdot 3$, which does not contradict our results.

In another study O'Fallon et al compared women with cancer of the breast with women with cholelithiasis and found that the use of thiazides by both groups was almost identical. ${ }^{9}$ Taking the view that cholecystitis and cholelithiasis are "interrelated," Porter et al considered that this finding contradicted an association between acute cholecystitis and use of thiazides. This line of reasoning is not correct: although acute cholecystitis and cholelithiasis are interrelated in the sense that most patients with acute cholecystitis have gall stones, the converse is not true and by no means all patients with gall stones develop acute cholecystitis. The finding that cholelithiasis per se is not associated with the use of thiazides ${ }^{9}$ must be viewed alongside the finding, which has now been reported twice, that thiazides are associated with acute cholecystitis, one of the complications of cholelithiasis. These two findings are compatible only if we assume that thiazides may help to induce acute cholecystitis in a patient with gall stones. This is the hypothesis that we have reached.

Rosenberg et al concluded their paper with the proviso that the association reported by them needed independent confirmation. We suggest that thiazides may induce acute cholecystitis in a patient at risk and that caution should be exercised when prescribing thiazides to patients with gall stones.

The recording of the data used in this study was made possible by financial support from Apoteksbolaget, Stockholm, and from Jämtland county council. This study was instigated by Dr Barbro Westerholm, director general of the Swedish National Health Board.

\section{References}

1 Rosenberg L, Shapiro S, Slone D, Kaufman DW, Miettinen OS, Stolley PD Thiazides and acute cholecystitis. $N$ Engl f Med 1980;303:546-8.

2 Porter JB, Jick H, Dinan BJ. Acute cholecystitis and thiazides. N Engl f Med $1981 ; 304: 954-5$

3 Van der Linden W, Edlund G. Early versus delayed cholecystectomy: the effect of a change in management. Br $\mathcal{F}$ Surg 1981;68:753-7.

4 Boethius G, Wiman F. Recording of drug prescriptions in the county of Jämtland, Sweden: methodological aspects. Eur $\mathcal{F}$ Clin Pharmacol 1977;12:31-5

5 Boëthius G. Prescriptions of drugs 1970-1975 in the county of Jämtland, Sweden. Department of Internal Medicine, Ostersund's Hospital, and Department of Clinical Pharmacology, Karolinska Institute, Sweden: 1977, 35 pp. (Thesis.) Miettinen

7 Berkson J. Limitations of the application of fourfold table analysis to hospital data. Biometrics Bulletin 1946;2:47-53.

8 Jackson-Beeck M, Kleinman JH. Evidence for self-selection among Health Maintenance Organisation enrollees. $\mathcal{F} A M A$ 1983;250:2826-9.

9 O'Fallon WM, Labarthe DW, Kurland LT. Rauwolfia derivatives and breast cancer. A case/control study in Olmsted county, Minnesota. Lancet 1975;ii:2926.

(Accepted 9 fuly 1984) 